\title{
TWO CASES OF "DECIDUOMA MALIGNUM."
}

By FREDERICK J. McCANN, M.D. (Edin.), F.R.C.S. (Eng.), M.R.C.P. (Lond.), Physician to In-patients, Samaritan Hospital for Women, London.

CASE 1. Patient alive and well two years after removal of the uterus by vaginal hysterectomy.

CASE 2. Patient died in hospital-secondary deposits in lungs and vagina.

CASE 1. A woman, aged 35 years, was sent to me at the Samaritan Hospital on July 13, 1901, by my friend Dr. Willan, of Dorking. She was very anæmic and had other signs of excessive blood loss.

History. Since April 1st, 1901, she had been losing blood daily from the vagina. It was supposed that she had had a miscarriage, but the history of the passage of ovuline structures was not definite. The amount of blood lost, which had increased three weeks before admission, had subsequently diminished. She had had four children, the youngest being aged three years. In August, 1900, she had a miscarriage at the second month, followed three weeks later by an attack of hæmorrhage lasting fourteen days. Her menstruation then became regular and continued so until April, 1901. She stated that she was getting thinner.

Bi-manual examination. The uterus was felt to be enlarged to the size of a three months' pregnancy, regular in outline, freely movable, and soft in consistence. I decided to operate on July 17th, 1901. The uterus was first dilated and examined with the finger. A distinct swelling was felt at the upper and back part of the uterine cavity. The mucous membrane covering it felt smooth and velvety. On attempting to separate this swelling at its lower part the finger could be introduced into the uterine wall, and the surrounding tissue made me suspicious that I had to deal with a malignant growth. The uterus was therefore removed by vaginal hysterectomy. The patient recovered and has remained well. The improvement in her condition has been most remarkable; she has gained flesh and her anæmia has disappeared. There is no evidence of recurrence up to the time of writing this paper (June, 1903).

The accompanying photograph, Fig. 1, is a representation of the uterus removed from this patient. The dark maroon colour of the growth was well seen on section. The uterus itself was plentifully supplied with blood vessels. Special care was taken during the operation to minimise the amount of blood loss, as the patient was already extremely anæmic. 


\section{Microscopical Examination.}

Low power. The muscular wall of the uterus is penetrated by strands of cells. The groundwork of the growth consists of a reticulated tissue containing in its meshes cells of different shapes. Multinucleated branching protoplasmic masses are seen. There is a considerable amount of fibrin and blood-clot in the specimen.

High power. The cells penetrating the muscular wall are found to be of three principal varieties: (1) Large cells with dark-stained nuclei rich in chromatin in which the cells' protoplasm is relatively clear; (2) smaller polyhedral nucleated cells; (3) irregular masses of multinucleated protoplasm of various sizes. In addition there is considerable infiltration with leucocytes. The reticulated tissue forming the groundwork of the growth is seen to contain in its meshes large rounded cells similar to those invading the muscular wall. In some of these the nuclei are undergoing division. There are also elongated cells containing one or more nuclei whose fusion may result in the formation of the multinucleated cell masses. The smaller polyhedral cells are now more apparent.

Numbers of large branching multinucleated masses are observed throughout the sections. Their nuclei are scattered irregularly in the cell protoplasm, and are deeply stained. The protoplasm in some of the cell masses is coarsely granular, and exhibits vacuoles, whilst in others granules cannot be seen, the protoplasm being either homogeneous or exhibiting slight linear marking. The abundance of blood-clot is a marked feature in all the sections.

CaSe 2. Mrs. W., aged 46 years, was admitted into the Samaritan Hospital under my care on March 19th, 1902. She was an extremely anæmic, sallow-complexioned woman.

History. She had had six children, the youngest being nine years of age. She never had a miscarriage. Her menstruation was regular and scanty, lasting only two days. In August, 1901, she had an attack of bleeding, clots and fluid blood being passed per vaginam. This hæmorrhage ceased and did not recur until the end of December, 1901. After this date there was daily loss of blood from the vagina. A fortnight previous to her admission she was examined by a doctor and afterwards she stated that the discharge became fœtid. She had very little abdominal pain, but with the onset of hæmorrhage she had considerable pain in the sacral region.

Her mother died aged 67 years of " something in the liver." Father died aged 77 years. No definite family history of malignant disease could be obtained.

State on examination. She was well nourished and stated that she had gained flesh. Her anæmia, however, was extreme, the mucous membrane being pallid. Dyspnca, on exertion, was marked.

Abdominal examination revealed a central swelling reaching to the midpoint between the umbilicus and the symphysis pubis, movable and painless. 
Vaginal examination. A brownish, watery, extremely offensive discharge issued from the vagina. Bi-manually the swelling above noted was found to be uterine and of the consistence of a soft myoma.

I decided to make an attempt under anæsthesia, to disinfect the uterine cavity. Her temperature varied between $100^{\circ} \mathrm{F}$. and $102^{\circ} \mathrm{F}$. with corresponding depressions. On March 26th, she was anæsthetised, and on introducing the finger into the uterine cavity (which did not require preliminary dilatation) the walls were found to be covered with irregular nodules readily breaking down. Several necrotic pieces came away on withdrawing the finger. One portion was preserved for microscopic examination, but owing to the extent of the necrosis the sections were unsatisfactory.

The vaginal walls were carefully examined and high up on the anterior wall a bluish nodule was detected, flattened and commencing to necrose on its surface. Its size corresponded to that of a sixpence. As this was obviously a secondary growth no operation was attempted. Douching was employed and the patient was returned to bed.

By the aid of douching and careful nursing her condition improved so much that she was able to leave her bed on April 15th. However, towards the end of that month her temperature began to rise higher, accompanied by increased weakness. The temperature was never below $99^{\circ} \mathrm{F}$. During the night of May 13th, a large quantity of discharge and dêbris was passed from the vagina, followed by a sudden fall in the temperature to $97^{\circ} \mathrm{F}$. The temperature remained about normal for three days, but the general condition of the patient was much worse. She began to suffer from increasing dyspnœa, and the physical signs led me to suspect secondary growths in the lungs. The distressed breathing daily increased, and she died on May 23rd, 1902.

A post-mortem examination was made the following day by Dr. Bosanquet.

Abdominal cavity. Peritoneal cavity normal, no peritonitis or free fluid. Uterus enlarged and adherent to neighbouring coils of intestine. A few enlarged glands along aorta at pelvic brim, whitish in colour, largest about the size of a cherry-stone, soft, not visibly affected with malignant disease

Liver. Large, $4 \mathrm{lbs}$, fatty and congested. No secondar'y deposits. Gall bladder contracted, no gall stones.

Spleen. 5 oz., pale, tough. No sign of disease.

Kidneys. Right, 5 ozs.; left, 6 ozs.; pale, fatty, much fat in pelves. Capsules strip readily, surface smooth.

Adrenals. Normal. 
Pancreas. Large, otherwise normal.

Stomach and Intestines. Much distended, no disease.

Cterus. Much enlarged, measuring about 4 inches vertically. Os patulous, easily admitting gloved finger which penetrates into a large cavity filled with blackish, somewhat offensive material. The uterus is practically converted into a thin-walled sac. At one point the wall ruptured on handling the organ, thus allowing the black contents to escape. Ovaries and tubes appear free from disease.

Thorax. Some adhesions in both pleural cavities due to masses of new growth in the lungs which have formed adhesions to the parietes. The lungs are studded with nodules of new growth, mostly cherry-red in colour. Some slightly umbilicated, most of them scattered indifferently about the lungs, but in places contiguous portions of the adjacent lobes are affected, some being adherent, others apparently separated by pleura. The largest nodule of growth is situated at the apex of the right lung somewhat anteriorly, and is 2 inches $\times 1 \frac{1}{2} \times 2$ in dimensions. The other nodules vary in size, from that of a pea to masses 1 inch in diameter.

On section the growths are reddish in colour, somewhat mottled, and in several of the nodules beside the reddish mass is a small nodule of a brownish-grey colour, the nature of which is not apparent without microscopical examination.

The bronchial and cervical lymphatic glands and the thyroid are not apparently affected.

Heart. Weighs 12 ozs., substance rather pale, valves and orifices normal.

\section{Microscopical Examination.}

Lungs. Numerous sections were cut from the secondary nodules present in the lungs. In the majority of these only blood and fibrin could be observed, although care was taken to obtain preparations which included the margin of the nodules. In a fow, however, some rounded nucleated cells were demonstrated. None of the sections showed protoplasmic masses.

Vagina. No cellular structure was found in the preparations made from the secondary nodule in the anterior vaginal wall. The entire specimen was composed of fibrin and blood.

Uterns. Low power. Sections made from the wall of the uterus when examined under a low power show that the uterine muscle is penetrated by rounded cells with large nuclei, and also by irregular elongated masses of protoplasm. There is marked infiltration with leucocytes, and abundance of fibrin and blood-clot.

High power. The rounded cells above mentioned are seen to be large in size. Their nuclei, rich in chromatin, stain deeply, whereas the surrounding protoplasm absorbs the stain to a lesser degree. Similar cells exist in large numbers in all the specimens, and invade the uterine muscle in different directions. Some elongated "oat-shaped" cells tapering at both ends and possessing a dark-stained central nucleus are scattered throughout the specimen. In addition smaller polyhedral nucleated cells are seen.

The elongated protoplasmic masses appear to be broken up in all the specimens; some contain nuclei, others do not. This may be a degenerative change which has resulted in their distintegration, or may be due to the advanced stage of the disease. 
Many of the muscular fibres of the uterus are swollen and cedematous. This effect is doubtless produced by the necrotic changes occurring in the growth. The marked infiltration with leucocytes is an evidence of the surrounding inflammatory reaction. No structure corresponding to a villus can be detected.

On studying these cases it must be admitted that the patient in Case 1 may have had a miscarriage, although her own evidence and that of her medical attendant was against this assumption. In the second case and in that already reported in the March (1903) number of this JounNal the occurrence of a recent pregnancy was not proven.

It seems, therefore, that in order to explain the incidence of the disease in the two last cases we must invoke the assistance of the theory that some fotal relics had remained in utero, and had formed a starting point for the new growth.

Although the origin of the new growth from the coverings of the villi has now been conclusively demonstrated in many cases, I think it is well for the present to retain the title "deciduoma malignum," for under this term we can include not merely cases in which the origin of the disease may be directly proved, but others in which the proof is not complete.

Cases of "deciduoma malignum" have been in the past described either as sarcomata or carcinomata, but the more accurate pathological investigations employed at the present time, together with the interest aroused in the elucidation of this disease, have been the means of identifying many examples which had been placed in museums and labelled cancer or sarcoma.

The occurrence of six cases of "deciduoma malignum" at the Samaritan Free Hospital within the last three years has made me doubt the excessive rarity of the malady, and I feel sure cases will be more frequently reported in the future.

It is probable, too, that the degree of malignancy has been overestimated. This is doubtless subject to considerable variation, some types exhibiting excessive malignancy, whilst others, especially the polypoid or circumscribed types, show this character to a lesser degree. Case 1 is an example of what may be termed the polypoid or circumscribed type. Case 2 represents the diffuse type in which the growth is diffused throughout the uterine mucous membrane, whilst the case previously reported in the March number of this JourNal furnishes yet a third type where the uterine cavity is filled with blood clot, and may be described as the "hæmorrhagic type." Examples of the last have been recorded under the title of sarcoma teleangiectodes, cavernous or angio-sarcomata of the uterus, and 


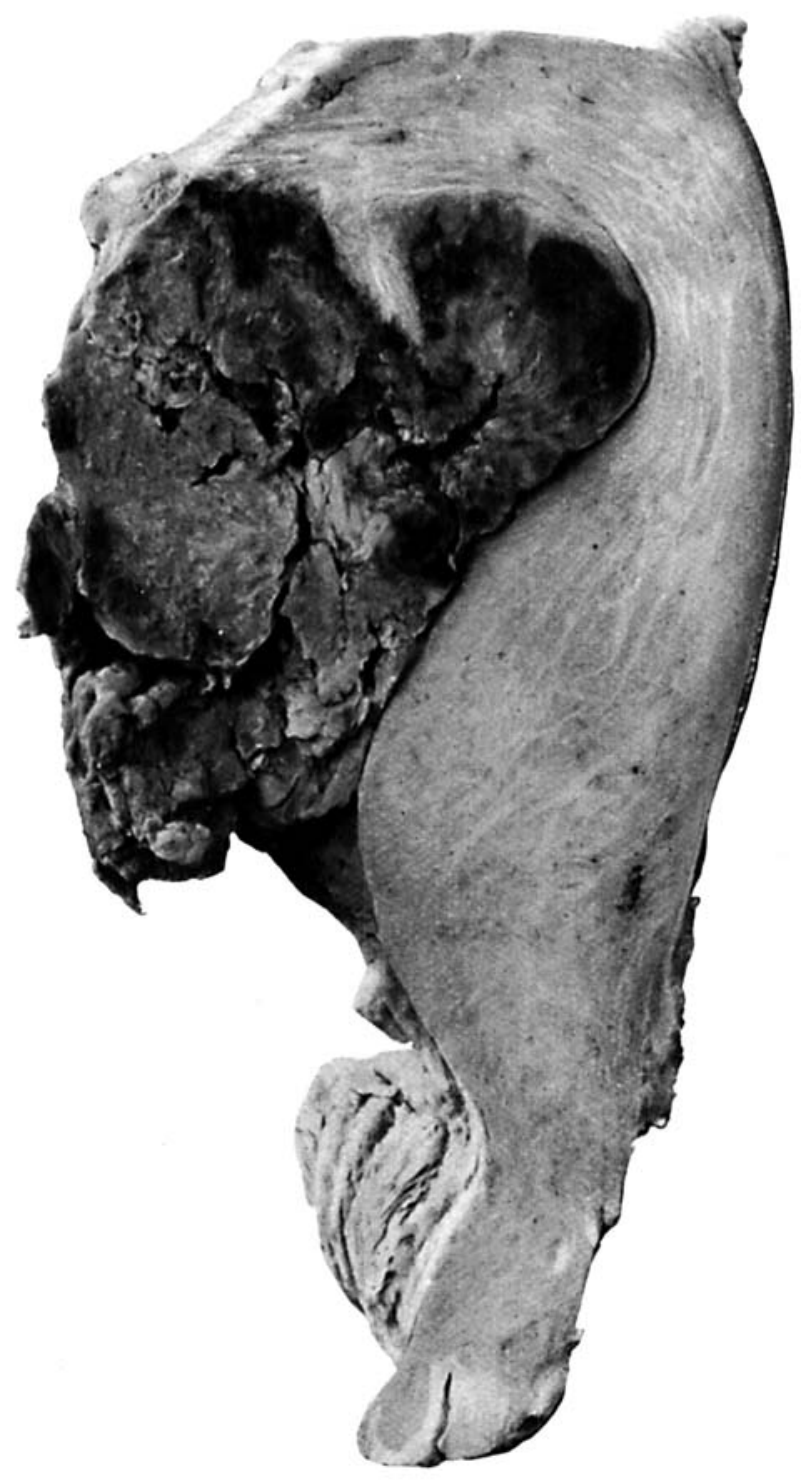

Fig. 1. 


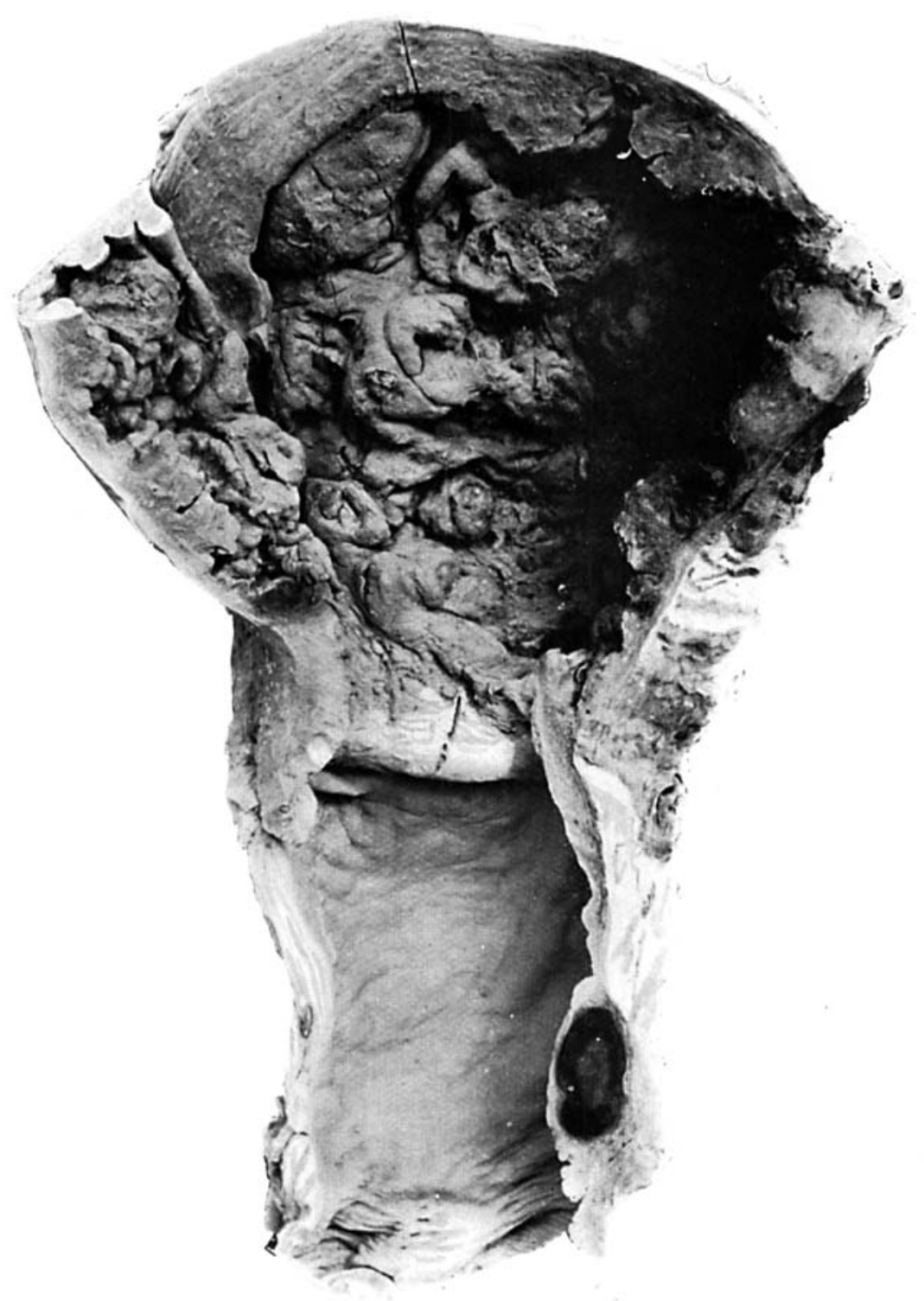

Fig. 2. 


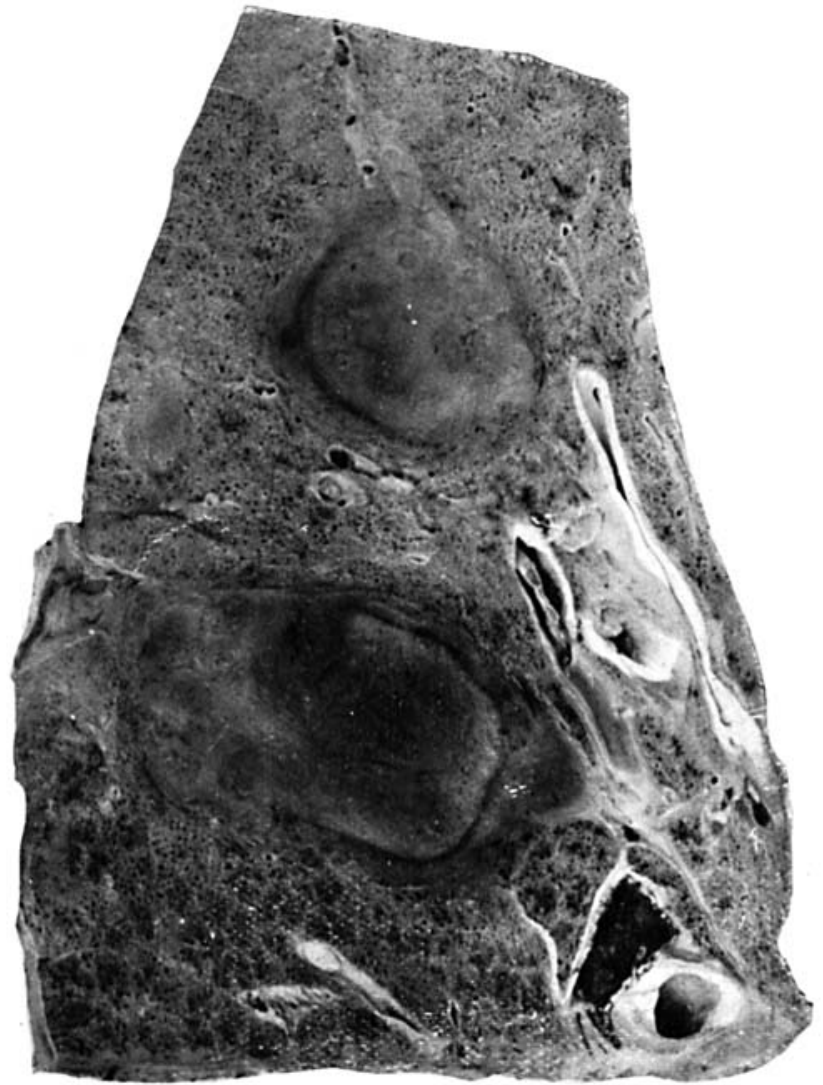

Fig. 3. 
have all been characterised clinically by the occurrence of most profuse hæmorrhage with considerable accumulation of blood and clot in utero. They appear to be comparatively rare.

Considerable interest attaches to cases in which the secondary deposits are alleged to have disappeared. If this be fully proved then we are justified in dealing surgically with cases in which secondary nodules exist in the vagina, unless the general condition of the patient contra-indicates any operative interference.

Let me add in conclusion that if we are to solve the many important problems connected with this disease it will be by careful and accurate records of cases without having in view the support of any theory as to the causation.

\section{Description of Figures.}

Fig $I$ is a reproduction of a photograph of the uterus in section (natural size). (Case I.)

The growth, which was covered by intact smooth mucous membrane, was assuming a polypoid shape.

The irregularity apparent at the lower part of the growth was caused by manipulations during the digital exploration.

The growth is seen to invade the uterine wall, whilst the wall itself is hypertrophied.

On section the growth was of a dark maroon colour owing to its vascularity, and was extremely soft in consistence.

FIG. 2. The photograph represents the uterus and vagina removed post-mortem.

The cavity of the uterus has been laid open to show the irregular nodulated condition of its interior. The growth is diffused over the whole of the inner surface, and has penetrated into the muscular wall of the uterus. As a result marked thinning of the uterine substance has been produced so that perforation occurred at one point during the removal of the organ from the body.

Under the mucous lining of the anterior vaginal wall a "secondary nodule" is seen.

FiG. 3. Represents a portion of a lung from the same patient, showing "secondary deposits" in the pulmonary substance. 